\title{
EFFECT OF TETRALIN ON POLYMER DEGRADATION IN SOLUTION
}

\author{
$\operatorname{le} 921204$ \\ submitted to \\ Industrial and Engineering Chemistry Research
}

by

Giridhar Madras, J.M. Smith, and Benjamin J. McCoy"

Department of Chemical Engineering and Materials Science

University of California at Davis

Davis, CA 95616

\section{DISCLAIMER}

This report was prepared as an account of work sponsored by an agency of the United States Government. Neither the United States Government nor any agency thereof, nor any of their employees, makes any warranty, express or implied, or assumes any legal liability or responsibility for the accuracy, completeness, or usefulness of any information, apparatus, product, or process disclosed, or represents that its use would not infringe privately owred rights. Reference herein to any specific commercial product, process, or service by trade name, trademark, manufacturer, or otherwise does not necessarily constitute or imply its endorsement, recommendation, or favoring by the United States Government or any agency thereof. The views and opinions of authors expressed herein do not necessarily state or reflect those of the United States Government or any agency thereof.

\footnotetext{
- Author to whom correspondence should be addressed. E-mail : bjmccoy@ucdavis.edu
} 


\section{DISCLAIMER}

Portions of this document may be illegible in electronic image products. Images are produced from the best available original document. 


\section{Abstract}

The effect of a hydrogen-donor solvent (tetralin) on the thermal degradation of poly(styrene-allyl alcohol) in solution was investigated in a steady-state tubular flow reactor at $1000 \mathrm{psig}(6.8 \mathrm{MPa})$, at various tetralin concentrations $(0-50 \%)$, polymer concentrations $(1-4 \mathrm{~g} / \mathrm{L})$, and temperatures $(130-200 \mathrm{C})$. The molecular weight distributions of the effluent at each condition were examined as a function of residence time by gel permeation chromatography. In the presence of tetralin, the polymer degrades by depolymerization to specific low molecular weight compounds and by random chain scission. No reaction was observed in the solvent 1-butanol in the absence of tetralin. The experimental data were interpreted with a rate expression first-order in polymer concentration based on continuous mixture kinetics, and rate coefficients were determined for the specific and random degradation processes. Activation energies were in the range of $5-10 \mathrm{kcal} / \mathrm{mol}$ for specific degradation and $33 \mathrm{kcal} / \mathrm{mol}$ for the random degradation process. A plot of rate coefficients versus tetralin concentration indicates a first-order rate at low tetralin concentrations and a zero-order dependence at high tetralin concentrations. 


\section{Introduction}

The thermal degradation of polymers is of considerable importance from both practical and theoretical points of views (Allen and Edge, 1992):

- the degradation of polymers in high-temperature environments can limit their applications (Hawkins, 1984);

- induced degradation can potentially be used in recycling waste plastics (Powell, 1990; Miller, 1994);

- thermal degradation by pyrolysis coupled with gas chromatography is an important analytical procedure for identifying polymeric structure (Flynn and Florin, 1985).

Thermolytic degradation of polymers is similar in some respects to other important thermal decomposition processes, e.g., petroleum cracking and coal thermolysis. All these processes involve complex mixtures, both as reactants and as products.

Simha and Wall (1958) and Jellinek (1955) did some early work on the degradation of polymers by measuring the yield of monomer, rate of decrease of molecular weight, and rate of volatilization. They developed rate expressions using free-radical mechanisms. This research was later followed by Madorsky (1964) who reviewed data on rates, activation energies, and experimental methods for thermal degradation for a variety of polymers. Later, Jellinek $(1978,1983)$ edited two books that analyze and critique various methods for measuring degradation rates. Recently, Hamid et al. (1992) published a comphrensive book on degradation.

A few experimental and theoretical investigations address the kinetics and mechanisms of polymer degradation (Reich and Stivala, 1971; Hawkins, 1984; Kehlen et al., 1988). These studies involved the determination of the average molecular weight 
(MW) of the polymer or the molecular weight distribution (MWD), and the identification of intermediate and final products. Various mechanisms and rate equations for each mechanism were proposed (Jellinek, 1983; Ziff and McGrady, 1985, 1986). The treatment of the general set of equations for initiation, propagation, transfer, and termination reactions can be classified by two approaches:

a. A statistical theory of random breaking of links (Simha and Wall, 1958; Wall, 1962; Jellinek, 1978) was proposed, and all reactions that form the intermediates and the species were assumed to start from a monodisperse sample (single MW). The desired functions were either obtained by probability considerations of breakage of links, or by the solution of differential rate equations. However, since these theories were derived for a monodisperse polymer, it is difficult to extend the theories to polydisperse polymers.

b. Pyrolytic thermal degradation is a two phase process, with higher MW species remaining in the condensed phase and the lower MW compounds evaporating. Gordon (1961) and Boyd (1970) conducted experiments by evaporating the monomer from a polydisperse sample. They showed that the form of MWD remains unaltered through a mild degradation, but shifts to lower $M W$ values.

Though these two approaches are useful for studying polymer degradation, one cannot easily use them to obtain kinetic parameters. However, due to the advance of technology in analytical instrumentation, dynamic MWD data can be obtained by gel permeation chromatography (GPC) or other means (Cooper, 1989). The polymer degradation usually occurs in a polydisperse mixture, and observing the temporal change of MWD caused by degradation affords a means to test kinetic models. A continuousmixture approach is applicable for these cases, since it is based on mass balance equations that govern the temporal change of a distribution function (Aris and Gavalas, 1966; Cheng and Redner, 1990). 
This approach for polymer degradation was theoretically investigated by Ziff and McGrady $(1985,1986)$. McCoy (1993) proposed a framework for the continuous kinetics for addition and decomposition reactions in reversible oligomerization. Prasad et al. (1986) presented a continuous kinetics model for coal liquefaction, and Wang et al. (1994) applied continuous kinetics to coal thermolysis. Recently, Wang et al. (1995) investigated the degradation of poly(styrene-allyl alcohol) at various temperatures in t-butanol, and measured the rates of both specific and random scission.

To our knowledge, there is little information on the effect of hydrogen-donor solvents on polymer degradation in the liquid phase. However, the effect of hydrogendonor solvents has been investigated for coal liquefaction. The extensive literature on this subject, including generally accepted pathways for hydrogen transfer from a donor solvent, was summarized by Chawla et al. (1989). Tetralin is widely accepted as a hydrogen-donor solvent, though its involvement in the liquefaction process of coal is quite complex (Orchin et al., 1948; Curran et al., 1967). The major product of tetralin conversion is naphthalene. Various other hydrogen-donor solvents have been studied. Kuhlmann et al. (1985) showed that 1,2,3,10b-tetrahydrofluoranthene had a hydrogendonor capability nearly 20 times that of tetralin for the liquefaction of bituminous coal, while 9,10-dihydrophenanthrene was found to have a hydrogen-donor capability nearly 40 times that of tetralin (Whitehurst et al., 1980). Kamiya et al. (1983) later showed that hydrogen-donor capability is also dependent on the solid, since 9,10-dihydrophenanthrene was an order of magnitude more reactive than tetralin for the liquefaction of brown coal, while it was only 3-4 times more reactive for the decomposition of benzylphenylacetate. All these reactions were carried out at about $450 \mathrm{C}$ and under hydrogen pressure. Recently, Oviawe et al. (1993) measured the relative rate constants for hydrogen transfer for four different hydrogen-donors, namely, 9,10-dihydrophenanthrene, indan, 1,2,3,4tetrahydroquinoline, and tetralin at lower temperatures (300 C and $400 \mathrm{C}$ ) for the 
decomposition of benzylphenylether under inert atmosphere. They found that the rates are only slightly different.

Our present objectives are to investigate the effect of various parameters such as the concentration of the hydrogen-donor solvent, tetralin, the temperature, and residence time on both specific and random degradation of a soluble polymer. The reaction order of the rate of degradation is determined for polymer and tetralin concentrations. The experimental data are obtained by employing a steady state reactor, and the products analyzed using HPLC-GPC. An unique feature is the high pressure of the experiments, ensuring the reactions take place in the liquid phase. The experimental data for MWD's are interpreted by means of continuous-mixture kinetics.

\section{Experiments}

\section{Pre-treatment of the polymer}

The polymer used in this study is poly(styrene-allyl alcohol) (Polysciences, Inc.) of the number-average molecular weight 1100 . The polymer is pretreated to remove components in the lower molecular weight range, which would interfere with the analysis of the product peaks. A detailed explanation of the pre-treatment is also given by Wang et al. (1995). To pretreat the polymer, 50 grams of the polymer was dissolved in $500 \mathrm{ml}$ of tert-butanol in a 2 liter flask. Distilled water serves as a precipitating agent and is added drop by drop to the polymer solution. The polymer solution, heated to $40 \mathrm{C}$ on a heating plate, is continuously stirred with a magnetic stirrer. After $50-100 \mathrm{ml}$ of water has been added, the polymer starts to separate from the solution, and begins to precipitate as a swollen phase at the bottom of the flask. Another $1250 \mathrm{ml}$ of distilled water is slowly added to this solution. The liquid phase is decanted and the precipitate is dried in an oven at $60-65 \mathrm{C}$ for 2.3 hours until a constant weight is obtained. The precipitate (which is the pretreated polymer) is blanketed under nitrogen in a closed bottle to avoid oxidation. This 
method of pretreating polymers follows the method reported by Kamide and Matsuda (1989). The number average molecular weight of the treated sample is 1640.

Degradation experiments

The experiments were carried out at high pressure, 1000 psig $(6.8 \mathrm{MPa})$, to prevent the vaporization of the solvent, 1-butanol, at high temperatures and to ensure that the reaction of the polymer occurs in the liquid phase. The tubular flow reactor (stainless steel) was $0.45 \mathrm{~m}$ long with ID $0.029 \mathrm{~m}$. The detailed apparatus and the operation procedure were described in Zhang et al. (1992) and Wang et al. (1993). The apparatus can be divided into four sections: feed and pressurizing section, extraction section, temperature-control section, and the sample collection section. A piston-type (Tobul Accumulators) accumulator of a liquid volumetric capacity of one gallon was filled with the polymer solution and pressurized to 1000 psig with nitrogen. A preheater coil is wound around the reactor and this assembly is placed in an electric furnace. A thermocouple is placed in the reactor to continuously monitor the temperature of the flowing fluid. The temperature is controlled by a PID temperature controller (Omega Model - 2000) and recorded on a chart recorder (Varian Model 9176). The pressure is measured with a pressure gauge (Ashcroft).

The polymer solution is prepared by dissolving the polymer in 1-butanol at a known concentration. The polymer solution flows through the reactor, a water cooled heat exchanger, two pressure reduction valves placed in series, and finally exits through a rotameter. The flow rate (and hence the residence time of the fluid in the reactor) is controlled by the rotameter. Degradation experiments were carried out at three different polymer concentrations, four different temperatures, and four different tetralin concentrations to study the effects of these parameters on the rate of polymer degradation. At each condition, the experiment was conducted at four different residence times (i.e., four different flow rates). Since the flow rates were measured at ambient conditions, the 
residence times for each temperature were corrected with the density calculated from LeeKesler equation (Lee and Kesler, 1975). After reaching steady state, two $20 \mathrm{ml}$ samples were collected at each residence time for the HPLC-GPC analysis. Experiments of 1butanol and 10 to $50 \%$ tetralin, in the absence of polymer, were conducted at 150 to 200 $\mathrm{C}$ to investigate interactions between the solvents. The GPC analysis of samples from these experiments indicated no products.

The significant difference of these experiments compared to pyrolysis experiments in gas or vacuum is that all the reactions take place in the liquid phase, and thus the residence time for both the reactants and products is the same. Further, the mild temperatures limit the amount of random chain scission and eliminate repolymerization.

Analysis by HPLC-GPC

Before analyzing the effluent sample by HPLC, one needs to concentrate the sample and dissolve the reactant and products in tetrahydrofuran. Hence, $20 \mathrm{ml}$ of the effluent sample is concentrated to $4 \mathrm{ml}$ by evaporating the l-butanol under vacuum at 353 C. To ensure that boiling the polymer solution (with and without tetralin) at $353 \mathrm{~K}$ produced no reaction, samples before and after evaporation were tested in the HPLC. No change was observed.

The molecular weight distribution of the effluent samples was determined by gel permeation chromatography (GPC) using PLgel columns (Polymer Labs) in a high performance liquid chromatograph (Hewlett Packard 1050). For this purpose, two columns packed with crosslinked poly(stryene-divinyl benzene) of 100 and $500 \mathrm{~A}$ pore size, respectively, were used in series after a guard column. Tetrahydrofuran (THF, HPLC grade, Fisher Chemicals) was continuously pumped through the columns at a constant flow rate of $1 \mathrm{ml} / \mathrm{min}$. A sample of 100 microliters was injected at the start of each run and the ultraviolet detector was used to measure the absorbance of the compounds in the 
effluent samples. The wavelength of $254 \mathrm{~nm}$ was chosen since this wavelength provided the maximum absorbance of the reactant and products.

A final check for the HPLC-GPC measurement was to ensure that there was no association in solution or of column adsorption (Yau et al., 1979). This was accomplished by running preliminary experiments at various injection volumes, and velocity ranges, and by changing the mobile phase from THF to pyridine. No significant change in the MWD was observed in any of these cases.

The molecular weight corresponding to the retention time in the columns was calibrated with polystyrene samples obtained from Polymer Lab. The calibration procedure is described in detail by Wang et al. (1995).

\section{Mechanism}

The mechanism of degradation of polymer is similar to that of Wang et al. (1995). The thermal degradation of the polymer is of two kinds: random scission at any position along the polymer chain, and specific scission leading to specific products. Both types of scissions occur in the degradation of poly(styrene-allyl alcohol), as seen from Figure 1, which is the MWD plotted as concentration distribution ( $\mathrm{g} / \mathrm{L} \mathrm{MW}$ ) versus $\log _{10} \mathrm{MW}$. The figure shows three distinct peaks in the molecular weight range 100-500 indicating specific scission products. The higher $\mathrm{MW}$ range peak shifts to a lower $\mathrm{MW}$ range relative to the feed polymer indicating random scission.

Though only three distinct peaks are observed in the figure, we expect the formation of styrene, since it was observed by Wang et al. (1995). The styrene peak should appear at a MW of 104. However, since tetralin and styrene have comparable MW of 132 and 104, respectively, the peaks of these two compounds are superimposed. Lacking a method to distinguish styrene from tetralin, we therefore removed this peak from the chromatogram and its subsequent analysis. The remaining peaks in the effluent 
chromatograms were approximately of MW 162,222, and 486, respectively, and are proposed to be the oligomer of an allyl alcohol and a styrene molecule (SA), and an oligomer of two allyl alcohols and one styrene molecule (ASA), and a trimer of SA $\left((\mathrm{SA})_{3}\right)$. Any allyl alcohol (A) produced during the degradation would evaporate during the sample preparation.

The specific products other than the monomer are produced by intramolecular transfer, as described by Madorsky (1964) for the degradation of polystyrene. Wang et al. (1995) suggested a mechanism based on chain scission for the formation of S, SA, and ASA.

\section{Theoretical Model}

The theoretical model is similar to the one proposed by Wang et al. (1995). The MWD of the feed polymer is described by a gamma distribution. The parameters of the gamma distribution are obtained by calculating the zeroth, first, and the second moments of the experimental peak. This gamma distribution is used as the initial MWD in the kinetics model.

\section{Continuous Kinetics for Polymer Degradation}

A continuous mixture can be defined as a mixture of a very large number of different-size polymer molecules, whose distribution can be examined by a continuous index like the molecular weight. We assume that all the degradation products are dissolved in solution, that no repolymerization reactions occur, and that the flow reactor can be treated as a steady-state plug-flow reactor. Model equations based on continuous kinetics for polymer degradation were developed by Wang et al. (1995). 


\section{Results and Discussion}

For the degradation of poly(styrene-allyl alcohol) in the presence of $t$-butanol, both random and specific scission of the polymer occurred at 130-200 C and 1000 psig (Wang et al., 1995). However, in the present case of 1-butanol solvent, no degradation of the polymer was observed at these conditions in the absence of tetralin. This suggests that $t$ butanol acted as a mild hydrogen-donor. The chemistry of alcohols (Morrison and Boyd, 1966) suggests that the dehydration of the alcohol depends upon the ease of formation of the carbonium ion (a group of atoms that contains a carbon atom bearing only six electrons). During the process of dehydration, the carbonium ion loses a hydrogen ion to form the alkene. The ease of dehydration, according to Morrison and Boyd (1966), indicates that t-butanol is dehydrated more easily than 1-butanol, and therefore acts as a mild hydrogen-donor.

An experimental MWD and model simulation are presented in Figure 2. As explained earlier, a peak of styrene has been removed since the peak of tetralin is superimposed on it. The three distinguishable peaks, SA, ASA, $(\mathrm{SA})_{3}$, are the products of specific chain scission. The same products (S, SA, ASA, (SA) 3 ) are produced with either t-butanol or 1-butanol plus tetralin.

The parameters in the model are the parameters of the gamma MWD describing the feed polymer and the rate coefficients for specific and random degradation. The rate coefficients for specific degradation are determined from the equation (Wang et al., 1995):

$$
q=k_{i} p t
$$

where $p$ is the feed concentration (molll), $t$ is the residence time, and $q$ is the concentration of the specific product $(\mathrm{mol} / \mathrm{L})$. These concentrations are the zeroth moments of their MWDs divided by MW. Since the zeroth moment is the area under the curve, the area of each specific product peak was determined by numerical integration 
using the trapezoidal rule. The plots of $q$ versus $p$, shown in Figures $3-4$, tend to confirm the linear relationship for the experimental conditions. The slope of the line gives the rate coefficient for specific degradation, $\mathrm{k}_{\mathrm{i}}$. The rate coefficients for random degradation are obtained by fitting the experimental MWD data of random degradation with gamma distribution parameters, using the relationship derived by Wang et al. (1995).

The dependence of the specific and random degradation rate coefficients on the temperature, concentration of the polymer, and concentration of the hydrogen-donor solvent (tetralin) are shown in the Tables 1-3. The rate constants are independent of polymer concentration (Figure 5), confirming that the reactions for both specific and random degradation are first-order. This is consistent with the assumption of Wang et al. (1995).

The dependence of the rate coefficients on temperature is shown in Figures 6-7, and correspond to activation energies for random and specific degradation as given in Table 4. The dependence of the rate constants on the concentration of tetralin is shown in Figures 8 and 9 for $k_{i}$ and $k_{r}$, respectively. The plots are of the Langmuir type, first order at low tetralin concentrations and zeroth order at high tetralin concentrations, and were modeled by the following equation:

$$
k=\frac{k_{t 1} C_{t}}{1+k_{t 2} C_{t}}
$$

where $k$ is the rate constant and $C_{t}$ is the vol\% of tetralin. Parameters $k_{t 1}$ and $k_{t 2}$ are obtained by plotting the inverse of the rate versus the inverse of tetralin concentration and are given in Table 5. Tetralin is essential for the degradation of the polymer. A tetralin concentration of $25 \%$ produces rate coefficients nearly an order of magnitude higher than the rate coefficients obtained by Wang et al. (1995), who degraded the same polymer using t-butanol without tetralin. However, the activation energies for the specific and 
random degradation of the polymer by 1 -butanol and $25 \%$ tetralin are comparable to the activation energies for the specific and random degradation of the polymer by t-butanol.

Rough estimates for the conversion of the polymer to specific products were $1-3$ $\%$ for the 1-butanol and 5\% tetralin system at $150 \mathrm{C}$, and $10-14 \%$ for the 1-butanol and $25 \%$ tetralin system at $200 \mathrm{C}$. The conversion in the former case corresponds approximately to the conversion obtained by Wang et al. (1995) for the degradation of the polymer in t-butanol in the absence of tetralin.

\section{Conclusion}

The thermal degradation of solubilized poly(styrene-allyl alcohol) in a steady-state tubular flow reactor has provided reaction rate data for a range of operating conditions. The reaction was carried out by dissolving the polymer in 1-butanol and conducting experiments at various polymer and hydrogen-donor (tetralin) concentrations, and at different temperatures. It was found that the polymer degrades to four specific products whose MW is less than 500 , and the MWD of the reactant polymer shifts to lower MW indicating the occurrence of both specific and random scission of the polymer. A continuous-mixture model satisfactorily describes the experimental data. The effect of temperature on the rate coefficients was significant for both specific and random degradation with the activation energies of $5-10 \mathrm{kcal} / \mathrm{mol}$ and $33 \mathrm{kcal} / \mathrm{mol}$, respectively. The effect of tetralin concentration was first-order at low concentration and zero-order at high tetralin concentration. Tetralin was necessary for the degradation of the polymer and the rate coefficients were nearly an order of magnitude higher than the coefficients reported for the degradation of polymer in t-butanol without tetralin. This indicates that hydrogen-donor solvents may be used to advantage. 


\section{Acknowledgement}

The financial support of Pittsburgh Energy Technology Center Grant No. DOE DE-FG22-94PC94204, and of the University of California UERG is gratefully acknowledged. 


\section{References}

Allen, N.S.; Edge, M. Fundamentals of Polymer Degradation and Stabilization. Elsevier Applied Science, New York : 1966.

Aris, R.; Gavalas, G.R. On the Theory of Reactions in Continuous Mixtures. Phil. Trans. R. Soc., London 1966, A260, 351.

Boyd, R. H. The Relationship Between the Kinetics and Mechanism of Thermal Depolymerization. in Thermal Stability of Polymers, Conley, R. T., Ed., Marcel Dekker, Inc., New York : 1970; pp 47 - 85.

Chawla, B.; Keogh, R.; Davis, B.H. Effect of Coal properties, Temperature, and Mineral Matter upon a Hydrogen-Donor Solvent during Coal Liquefaction. Energy and Fuels, 1989, 3, 236242.

Cheng, Z., Redner, S. Kinetics of Fragmentation. J. Phys. A: Math. Gen. 1990, 23, 1233.

Cooper, A.R. In Determination of Molecular Weight. John Wiley and Sons, New York :1989; pp. $1-6$

Curran, G.P.; Struck, R.T.; Gorin, E. Mechanism of Hydrogen Transfer to Coal and Coal Extracts. Ind. Eng. Chem. Process. Des. Dev. 1967, 6, 166.

Flynn, J.H.; Florin, R.E. Degradation and Pyrolysis Mechanisms. In Pyrolysis and GC in Polymer Analysis. Liebman, S. A.; Levy, E.J., Eds., Marcel Dekker Inc., New York : 1985; pp 149208.

Gordon, M. Recent Advances in the Theory of Thermal Degradation of Heterodisperse Polymers. In Thermal Degradation of Polymers, SCI Monograph 13, Society of Chemical Industry, London : 1961; pp. 163 - 180.

Hamid, H.; Arin, M.B.; Maadhah, A.G. In Handbook of Polymer Degradation; M. Dekker, New York: 1992.

Hawkins, W. L. In Polymer Degradation and Stabilization; Springer-Verlag, New York : 1984.

Jellinek, H.H.G. In Degradation and Vinyl Polymers; Academic Press, New York : 1955.

Jellinek, H. H. G. In Degradation and Depolymerization Kinetics. In Aspects of Degradation and Stabilization of Polymers; Elsevier, Amsterdam : 1978 ; pp. 1-38.

Jellinek, H.H.G. In Degradation and Stabilization of Polymers; Vol. 1, Elsevier, New York : 1983.

Jellinek, H.H.G. In Encyclopedia of Polymer Degradation; Vol. 4., Wiley, New York : 1983. 
Kamide, K.; Matsuda, S. Fraction Methods for the Determination of Molecular Weight Distribution. In Determination of Molecular Weight; Cooper, A.R., Ed.; John Wiley \& Sons, New York : 1989; pp. 201-262

Kamiya, Y.; Nagae, S.; Yao, T. The Relative Effectiveness of Aromatic Solvents in the Liquefaction of Brown Coal and Bituminous Coal. Proc. Int. Conf. Coal. Sci. 1983, 8, 184.

Kehlen, H., Ratzsch, M.T.; Bergmann, J. Continuous Kinetics of First Order Degradation Reactions in Polydisperse Mixtures. Chem. Eng. Sci. 1988, 43 (3), 609.

Kuhlmann, E.J.; Jung, D.Y.; Guptill, R.P.; Dyke, C.A.; Zang, H.K. Coal Liquefaction Using a Hydrogenated Creosote Oil Solvent. Fuel 1985, 64, 1552.

Lee, B.F.; Kesler, M.G. A Generalized Thermodynamic Correlation based on Three-parameter corresponding states. AIChE. J. 1975, 21, 510-527.

Madorsky, S.L. In Thermal Degradation of Organic Polymers. Interscience, New York : 1964.

McCoy, B. J. Continuous-Mixture Kinetics and Equilibrium for Reversible Oligomerization Reactions. AIChE J. 1993, 39, 1827.

Miller, A. Industry Invests in Reusing Plastics. Environ. Sci. Tech. 1994, 28, 16A.

Orchin, M.; Storch, H.H. Solvation and Hydrogenation of Coal. Ind. Eng. Chem. 1948, 40, 1385.

Oviawe, A.P.; Nicole, D.; Frigant, J.L. Modelling of Hydrogen Transfer in Coal Hydroliquefaction. Fuel 1993, 72, 65-68.

Powell, C. S. Plastic Goes Green. Sci. American 1990, 101.

Prasad, G. N.; Agnew, N. J.; Sridhar, T. Modeling of Coal Liquefaction Kinetics Based on Reactions in Continuous Mixtures. Part I: Theory. AIChE J. 1986, 32, 1277.

Reich, L.; Stivala, S.S In Elements of Polymer Degradation; McGraw Hill, New York : 1971; pp. 164-228.

Simha, R.; Wall, L.A. Mechanisms of Polymer Formation and Decomposition. In Catalysis, Vol. 6. Rienhold, New York : 1958; Chapter 3.

Syamlal, M.; Wittmann, C.V. Continuous Reaction Mixture Model for Coal Liquefaction Kinetics. Ind. Eng. Chem. Fundam. 1985, 24, 82.

Wall, L. A. In Analytical Chemistry of Polymers. Part II. Kline, G. M., Ed.; Academic Press, New York : 1962; Chap. 5, pp. 181-248.

Wang, M.; Smith, J.M.; McCoy, B.J. Kinetics of Coal Thermolysis with a Mixed Solvent of tButanol and Tetralin. Energy \& Fuel 1993, 7, 78. 
Wang, M.; Zhang, C.J.; Smith, J.M.; McCoy, B.J. Continuous-Mixture Kinetics of Thermolytic Extraction of Coal in Supercritical Fluid AIChE J. 1994, 40, 131.

Wang, M.; Smith, J.M.; McCoy, B.J. Continuous-Mixture Kinetics for Thermal Degradation of Poly(Styrene-Allyl Alcohol) in Solution AIChE J. 1995, In press.

Whitehurst, D.D.;Mitchell, T.O.; Farcasiu, M. In Coal Liquefaction : The Chemistry and Technology of Thermal Processes. Academic Press, New York : 1980.

Yau, W. W.; Kirkland, J.J.; Bly, D.D. Modern Size-Exclusion Liquid Chromatography. John Wiley \& Sons, New York : 1979.

Zhang, C. J.; Smith, J.M.; McCoy, B.J. Kinetics of Supercritical Fluid Extraction of Coal: Physical and Chemical Processes. In ACS Symposium Series on Supercritical Fluids, No. 514, Chap. 29, 1992; pp 386.

Ziff, R. M.; McGrady, E.D. The Kinetics of Cluster Fragmentation and Depolymerisation. J. Phys. A: Math. Gen. 1985, 18, 3027.

Ziff, R. M.; McGrady, E.D. Kinetics of Polymer Degradation. Macromolecules 1986, 19, 2513. 
Table 1. Rate coefficients $(1 / \mathrm{sec})$ for specific and random degradation of the polymer at various temperatures and at a constant polymer concentration of $2 \mathrm{~g} / \mathrm{L}$ and a tetralin concentration of $25 \%$.

\begin{tabular}{|l|l|l|l|l|}
\hline Temperature & $\begin{array}{l}k \text { for SA } \\
\left(\times 10^{3}\right)\end{array}$ & $\begin{array}{l}k \text { for ASA } \\
\left(\times 10^{3}\right)\end{array}$ & $\begin{array}{l}k \text { for }(\mathrm{SA})_{3} \\
\left(\times 10^{3}\right)\end{array}$ & $k_{\mathrm{r}}\left(\times 10^{4}\right)$ \\
\hline 130 & 1.68 & 2.52 & 3.36 & 0.22 \\
\hline 150 & 1.89 & 3.09 & 4.05 & 2.1 \\
\hline 170 & 3.9 & 4.68 & 5.85 & 18 \\
\hline 200 & 5.95 & 6.43 & 7.14 & 130 \\
\hline
\end{tabular}


Table 2. Rate coefficients $(1 / \mathrm{sec})$ for specific and random degradation of the polymer at various polymer concentrations and at a constant temperature of $150 \mathrm{C}$ and a tetralin concentration of $25 \%$.

\begin{tabular}{|l|l|l|l|l|}
\hline Polymer Conc. & $k$ for SA & $k$ for ASA & $k$ for (SA)3 & k \\
$(\mathrm{g} / \mathrm{L})$ & $\left(\times 10^{3}\right)$ & $\left(\times 10^{3}\right)$ & $\left(\times 10^{3}\right)$ & $\left(\times 10^{4}\right)$ \\
\hline 1 & 1.73 & 3 & 4.2 & 2.3 \\
\hline 2 & 1.89 & 3.09 & 4.05 & 2.1 \\
\hline 4 & 1.75 & 2.89 & 3.9 & 2.3 \\
\hline
\end{tabular}


Table 3. Rate coefficients $(1 / \mathrm{sec})$ for specific and random degradation of the polymer at various tetralin concentrations and at a constant temperature of $150 \mathrm{C}$ and a constant polymer concentration of $2 \mathrm{~g} / \mathrm{L}$.

\begin{tabular}{|l|l|l|l|l|}
\hline $\begin{array}{l}\text { Tetralin } \\
\text { Conc. }\end{array}$ & $\begin{array}{l}\mathrm{k} \text { for SA } \\
\left(\times 10^{3}\right)\end{array}$ & $\begin{array}{l}\mathrm{k} \text { for ASA } \\
\left(\times 10^{3}\right)\end{array}$ & $\begin{array}{l}\mathrm{k} \text { for (SA) } 3 \\
\left(\times 10^{3}\right)\end{array}$ & $\begin{array}{l}\mathrm{k}_{\mathrm{r}} \\
\left(\times 10^{4}\right)\end{array}$ \\
\hline $5 \%$ & 0.58 & 1.6 & 1.78 & 0.4 \\
\hline $10 \%$ & 0.8 & 2.3 & 2.5 & 1.0 \\
\hline $25 \%$ & 1.89 & 3.09 & 4.05 & 2.1 \\
\hline $50 \%$ & 2.09 & 3.57 & 4.9 & 2.5 \\
\hline
\end{tabular}


Table 4. Activation energies for specific and random degradation

\begin{tabular}{|l|l|}
\hline Specific Product & Activation energies $(\mathrm{kcal} / \mathrm{mol})$ \\
\hline SA & 7.5 \\
\hline ASA & 5.2 \\
\hline$(\mathrm{SA})_{3}$ & 4.4 \\
\hline Random degradation & 33.1 \\
\hline
\end{tabular}


Table 5. Parameters for the dependence of rate coefficients of polymer degradation on tetralin concentration.

\begin{tabular}{|c|c|c|}
\hline Specific Product & $\begin{array}{l}k_{t 1}\left(\times 10^{4}\right) \\
\left(1 / \mathrm{sec} / v^{\prime} \%\right)\end{array}$ & $\begin{array}{l}\mathrm{k}_{\mathrm{t} 2} \\
(1 / \mathrm{vol} \%)\end{array}$ \\
\hline SA & 1.33 & 0.043 \\
\hline ASA & 5.59 & 0.138 \\
\hline$(\mathrm{SA})_{3}$ & 4.96 & 0.085 \\
\hline Random degradation & 1.07 & 0.012 \\
\hline
\end{tabular}




\section{Figure Captions}

1. The MWD before and after thermal degradation ( $D$ : chromatograph before degradation, _ : Gamma Distribution fit ; $\mathbf{\Delta}$ : chromatograph after degradation at 150 C, $25 \%$ tetralin, and residence time of $42.51 \mathrm{~min}$. ; : Gamma Distribution fit).

2. Comparison of experimental results of MWD with model simulation at $150 \mathrm{C}, 25 \%$ tetralin, and at four residence times ( $42.51 \mathrm{~min}, 28.34 \mathrm{~min}, 21.25 \mathrm{~min}, 12.75 \mathrm{~min}$ ).

3. The plot of $q / p$ for the three specific products and residence time to determine the rate coefficients at different temperatures.

4. The plot of $q / p$ for the three specific products and residence time to determine the rate coefficients at different tetralin concentrations.

5. Plot of the specific degradation coefficients $(1 / \mathrm{sec})$ versus polymer concentration to determine the order of the rate of degradation of the polymer.

6. Arrhenius plot of the specific degradation coefficients versus temperature to determine the activation energies of the specific degradation for each product.

7. Arrhenius plot of the random degradation coefficients versus temperature to determine the activation energies of random degradation of the polymer.

8. Plot of the specific degradation coefficients ( $1 / \mathrm{sec})$ versus tetralin concentration.

9. Plot of the random degradation coefficients (1/sec) versus tetralin concentration.

Legend for Figures 3, 4, 6, 8:

- sa - ASA $\bullet$ (SA)3 


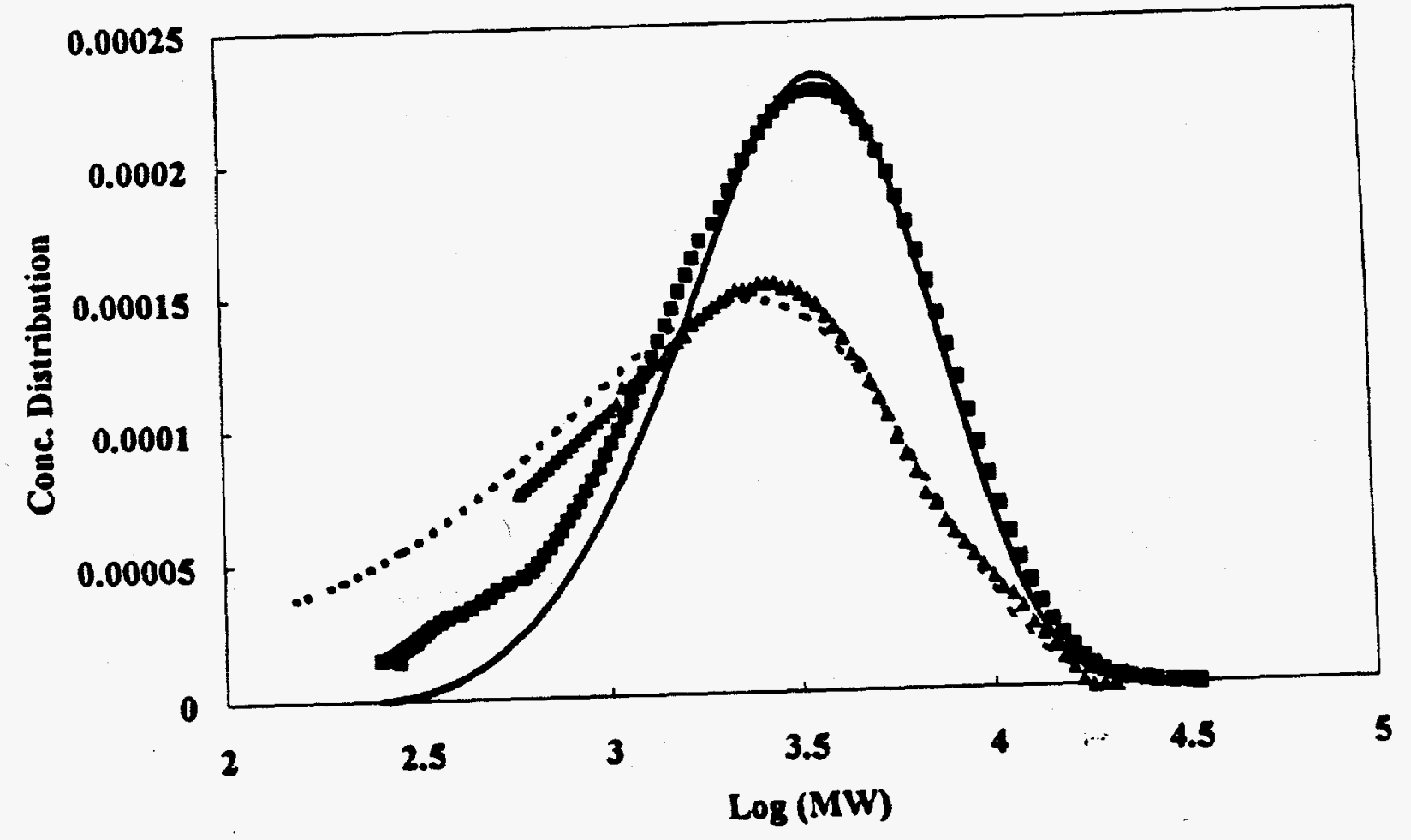

Figure 1. The MWD before and after thermal degradation ( $:$ chromatograph before degradation, - Gamma Distribution fit ; 4 : chromatograph after degradation at 150 C, $25 \%$ tetralin, and residence time of $\mathbf{4 2 . 5 1} \mathrm{min}$; ....... : Gamma Distribution fit). 

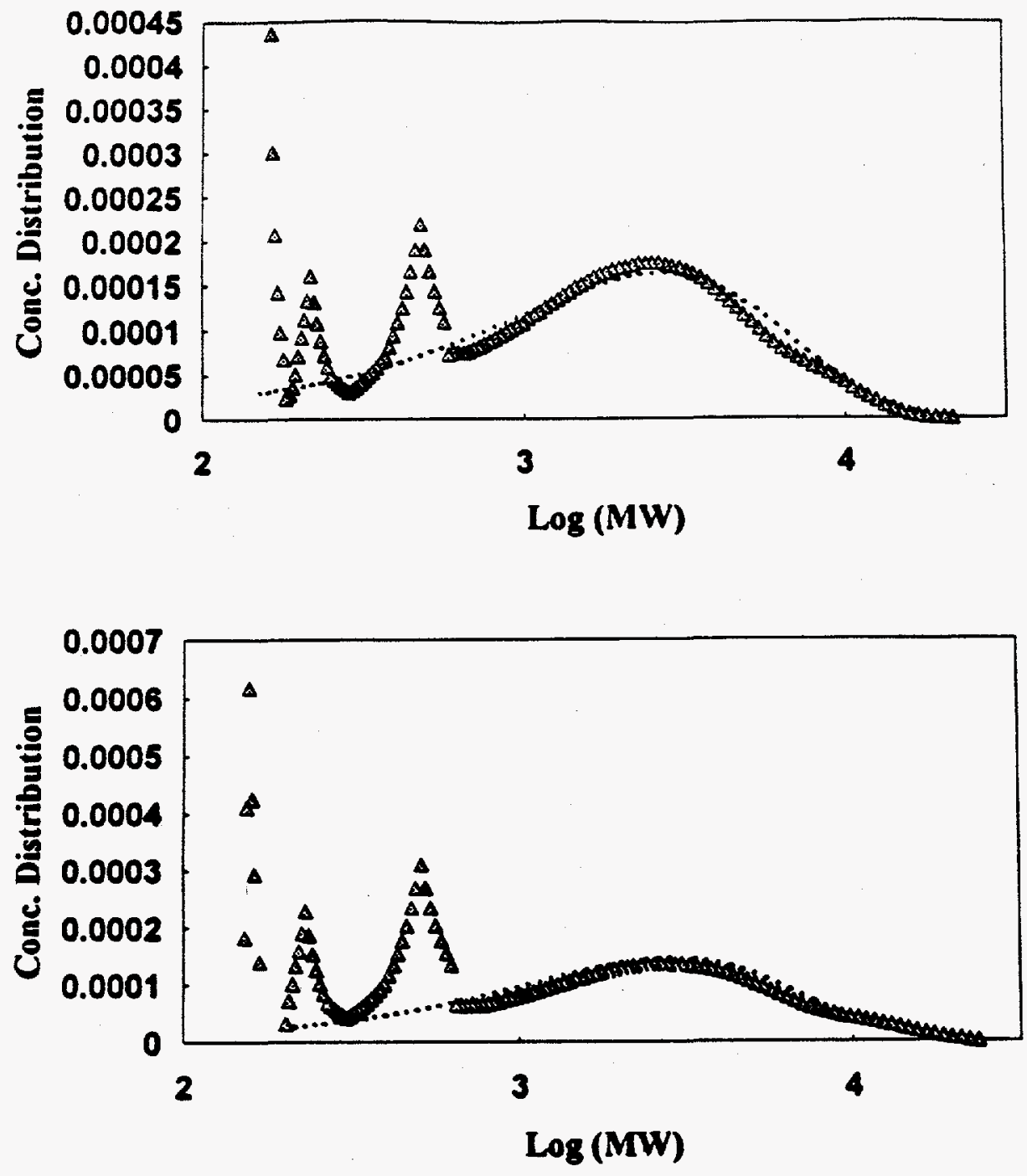

Figure 2. Comparison of experimental results of MWD with model simulation at $150 \mathrm{C}$, $25 \%$ tetralin, and at four residence times (42.51 min, $28.34 \mathrm{~min}, 21.25 \mathrm{~min}, 12.75 \mathrm{~min}$ ). 

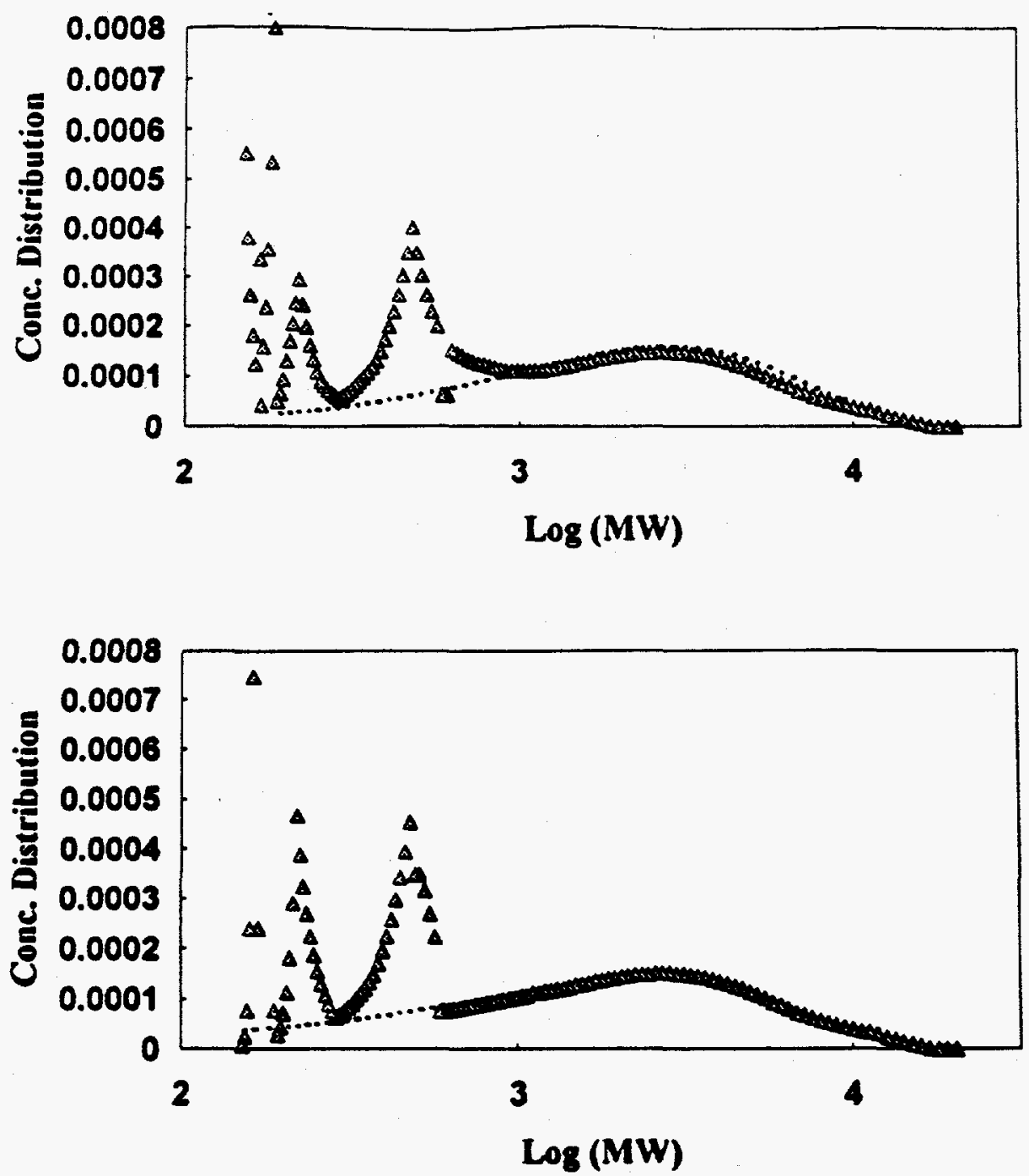

Figure 2. (contd.). 
$130 \mathrm{C}$

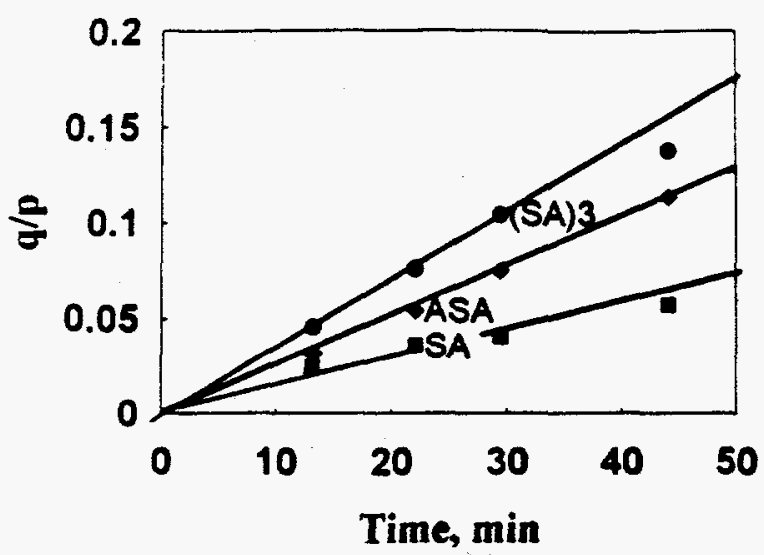

$170 \mathrm{C}$

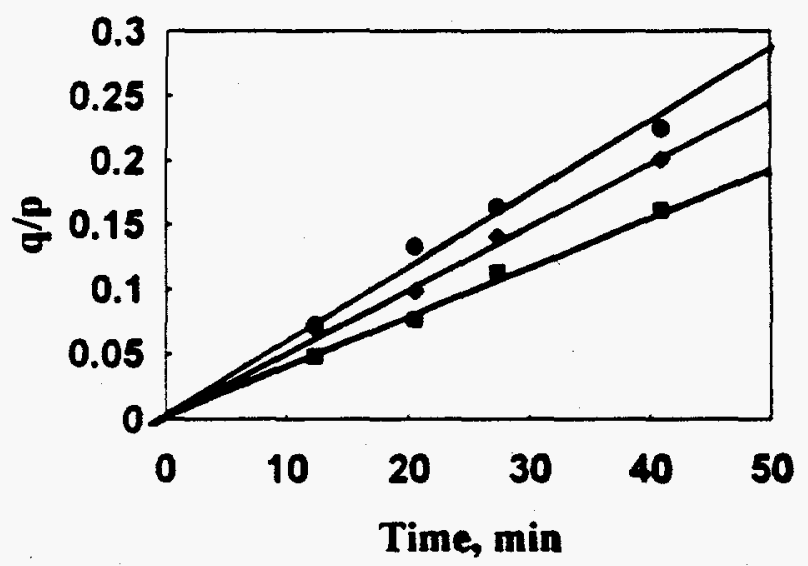

$150 \mathrm{C}$

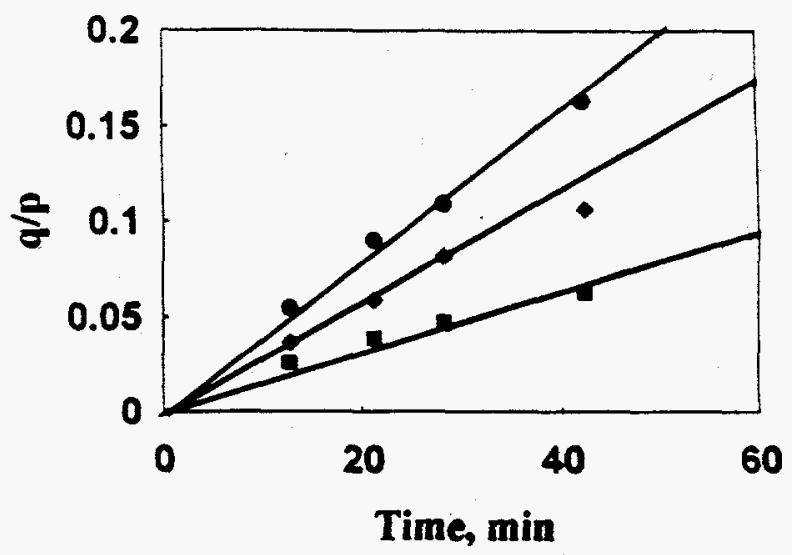

$200 \mathrm{C}$

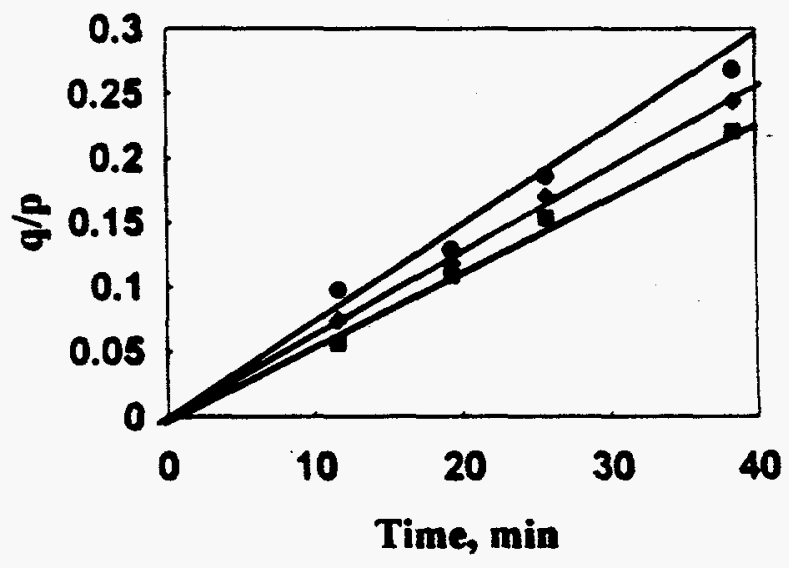

Figure 3. The plot of $q / p$ for the three specific products and residence time to determine the rate coefficients at different temperatures. 
5* Tetralin

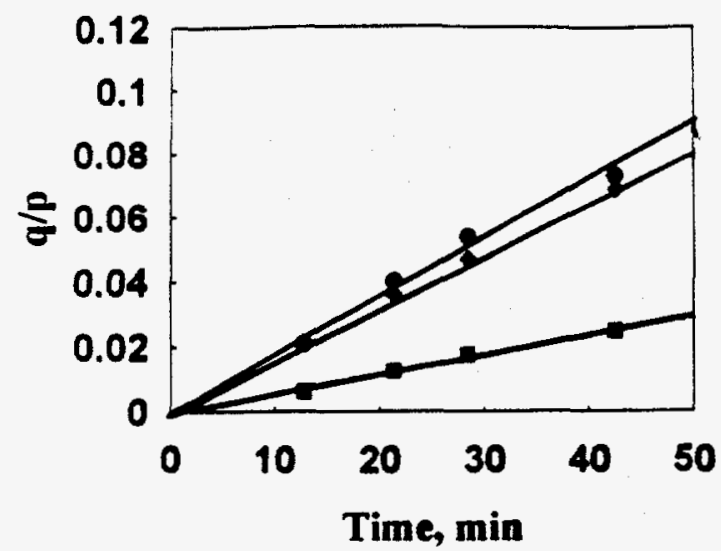

25* Tetralin

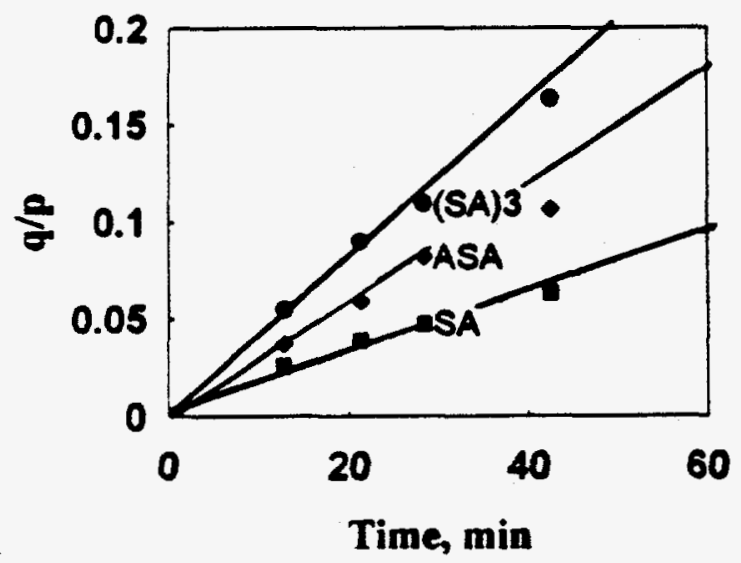

10\% Tetralin

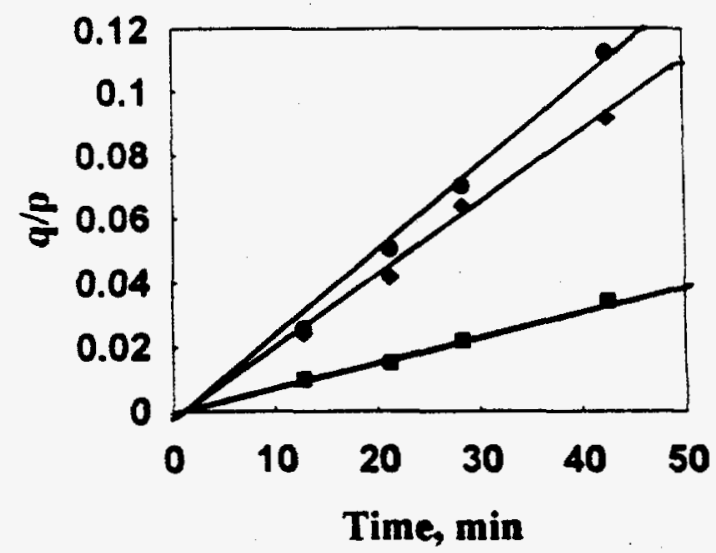

sof Tetralin

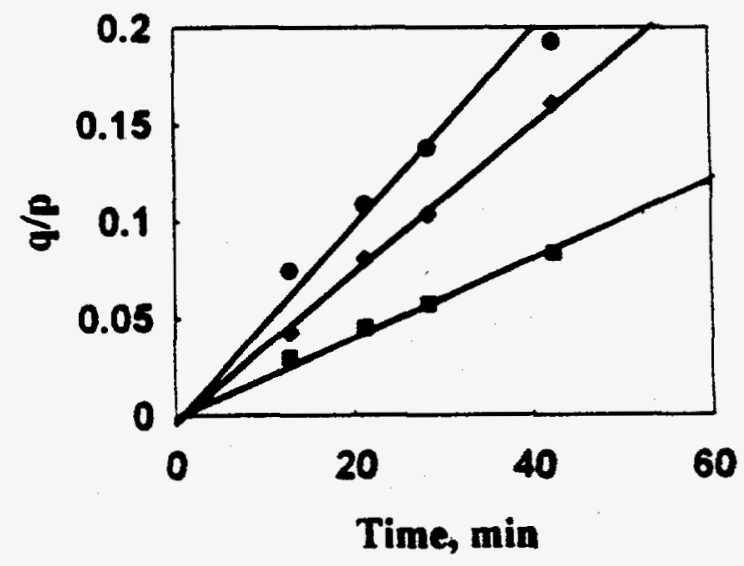

Figure 4. The plot of $q / p$ for the three specific products and residence time to determine the rate coefficients at different tetralin concentrations. 


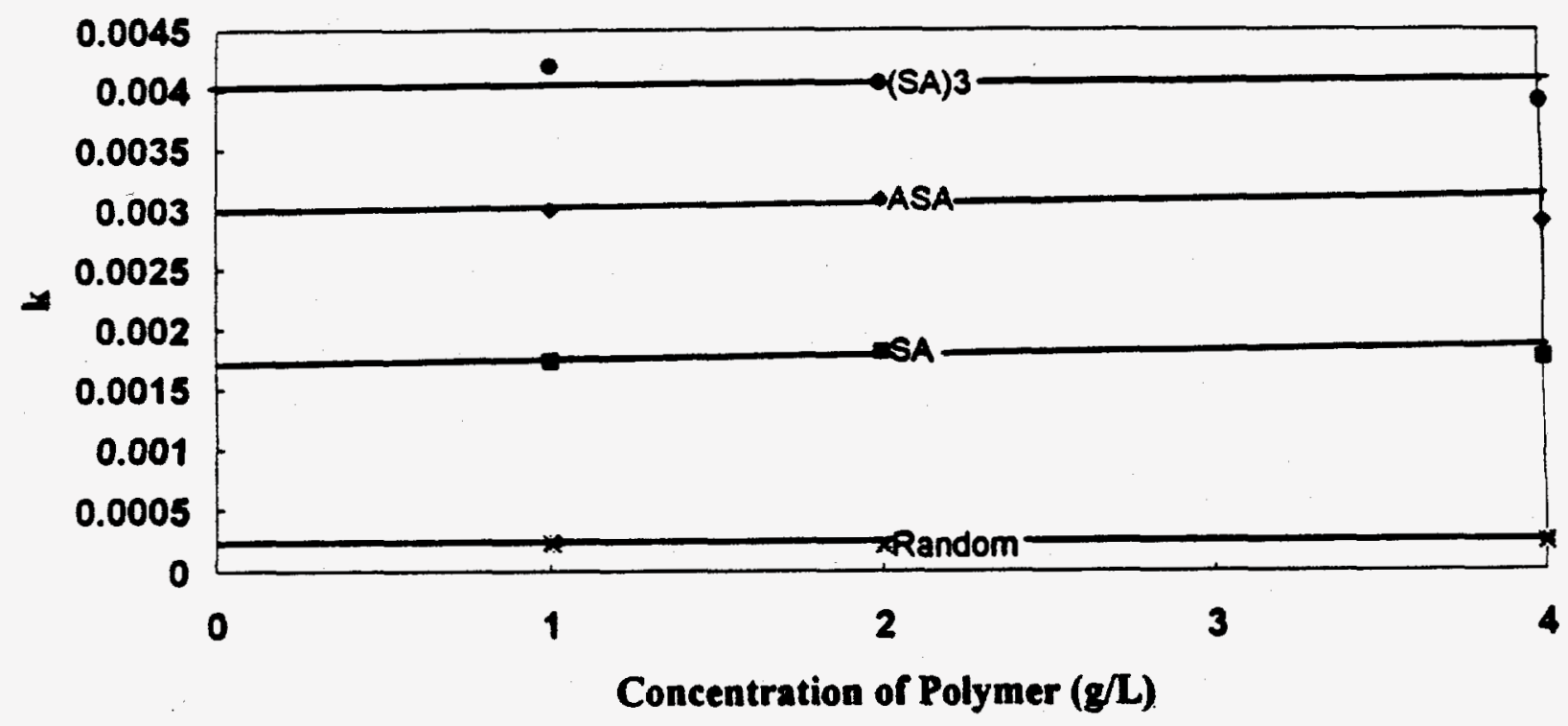

Figure 5. Plot of the specific degradation coefficients ( $1 / \mathrm{sec})$ versus polymer concentration to determine the order of the rate of degradation of the polymer. 


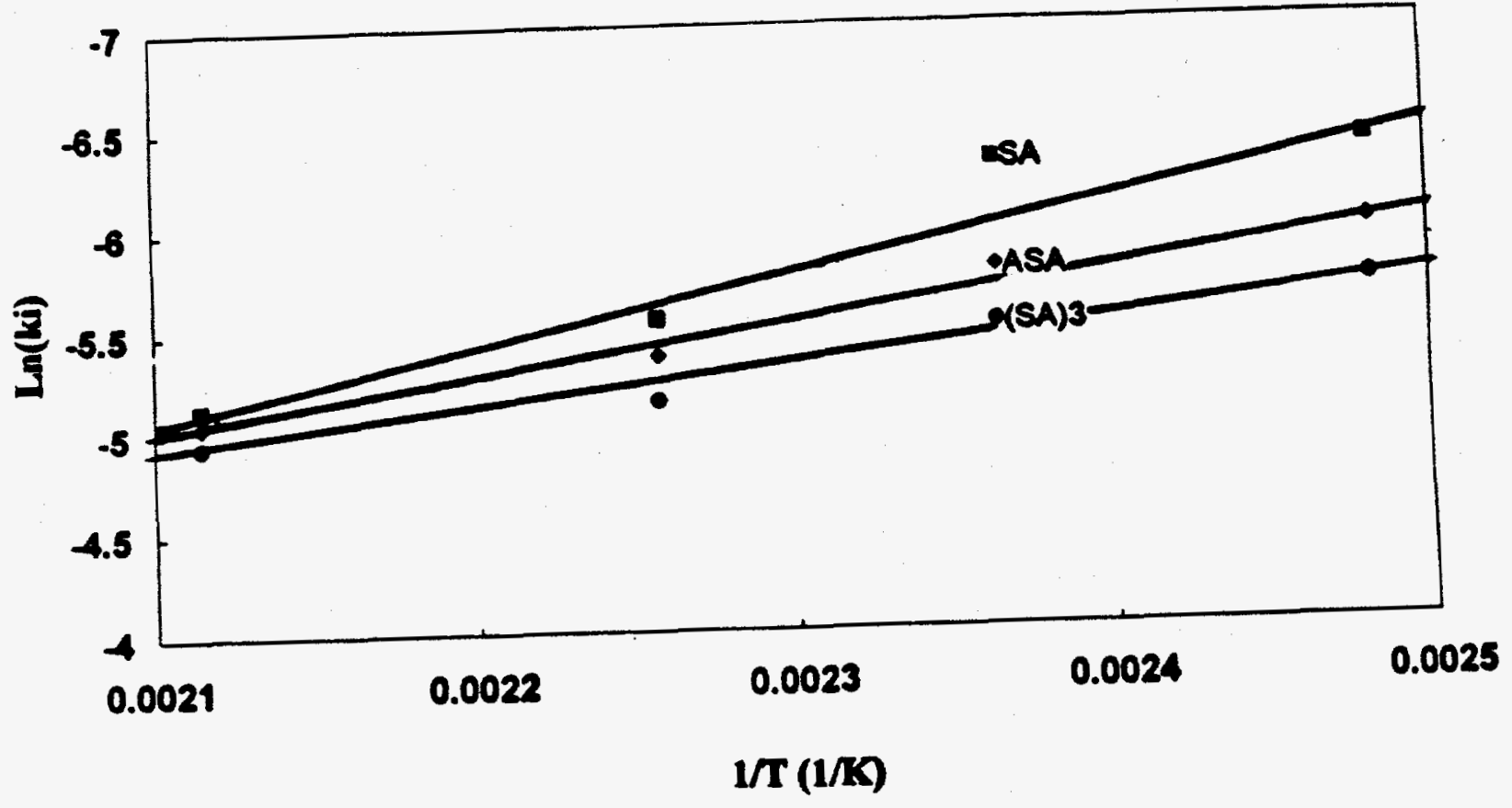

Figure 6. Arthenius plot of the specific degradation coefficients versus temperature to determine the activation energies of the specific degradation for each product. 


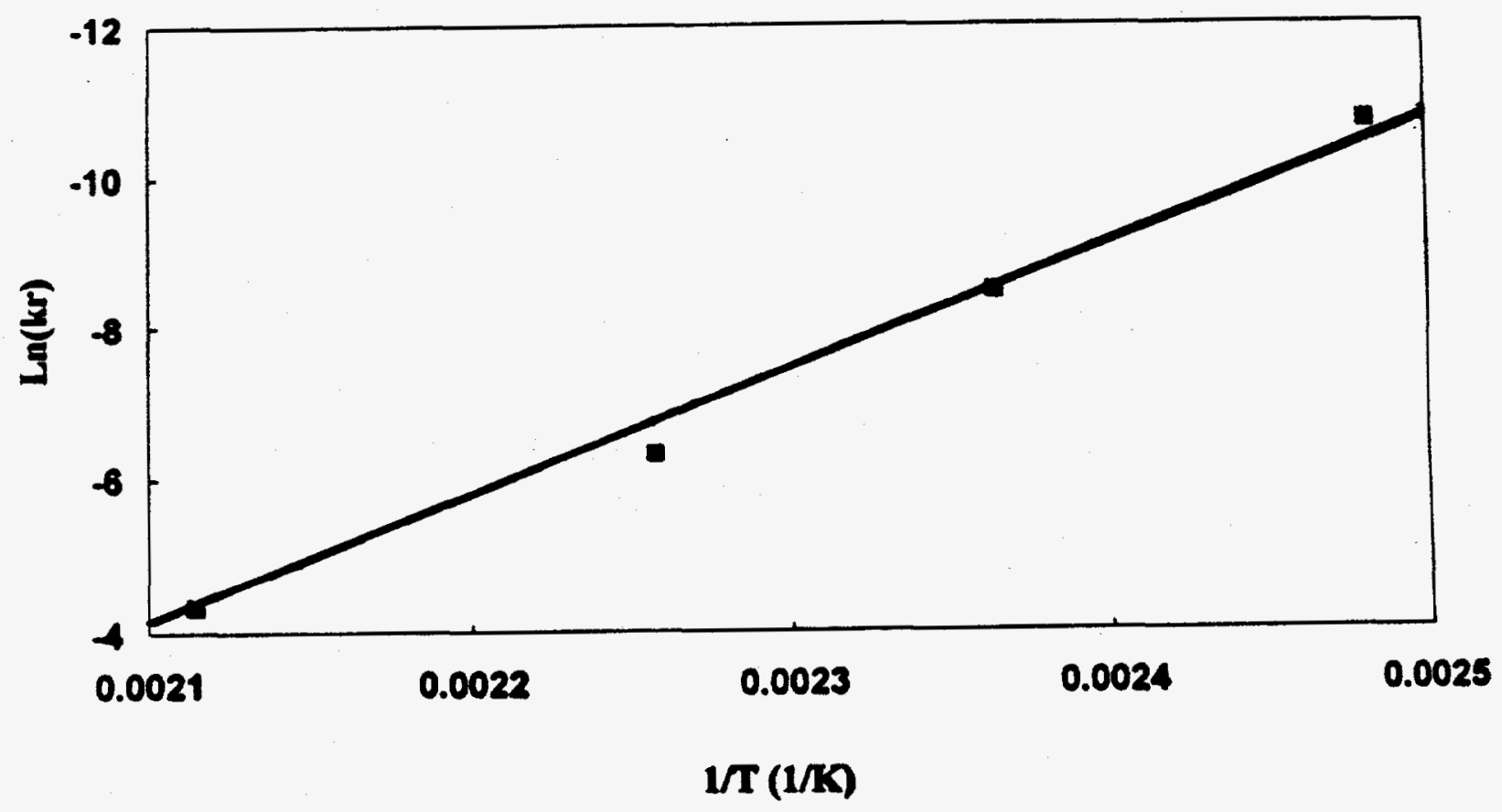

Figure 7. Arrhenius plot of the random degradation coefficients versus temperature to determine the activation energies of random degradation of the polymer. 


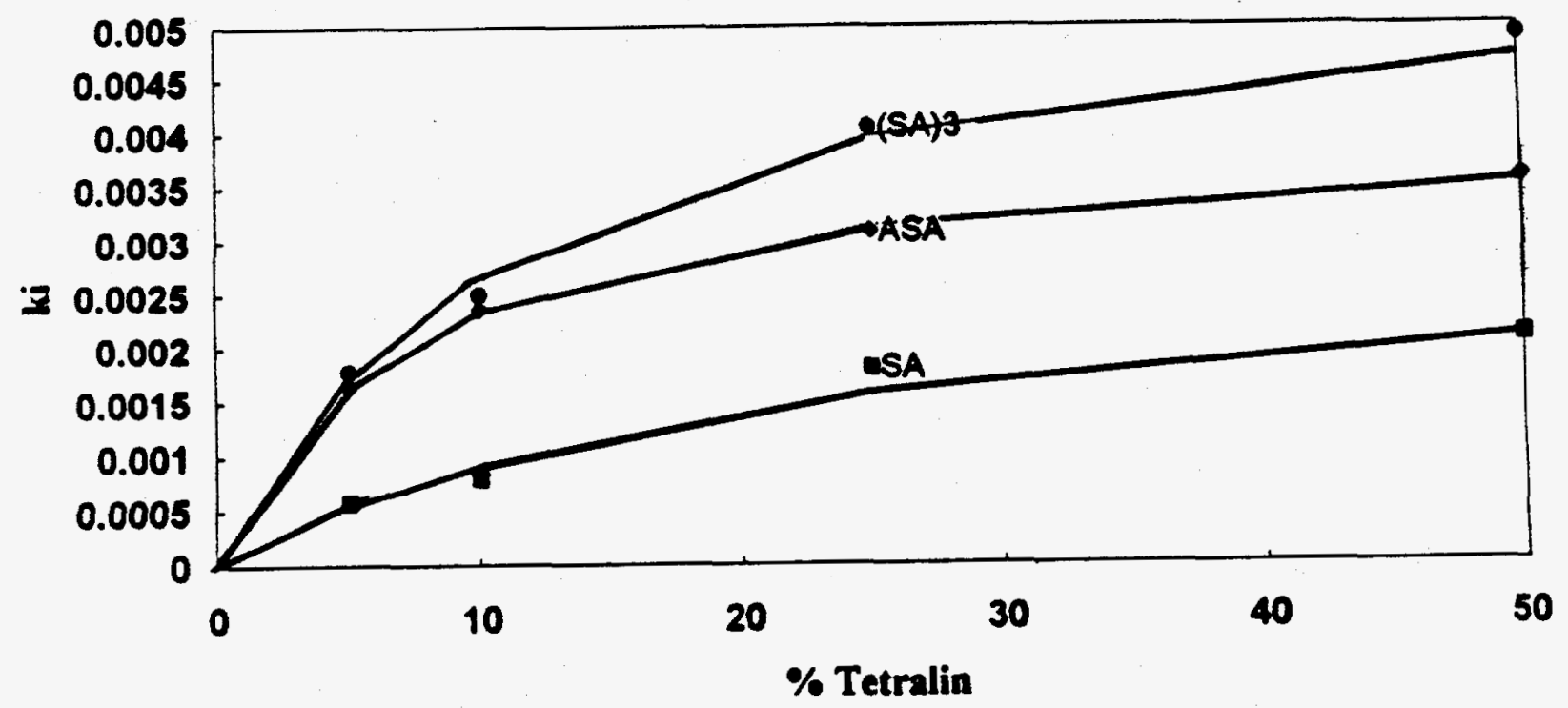

Figure 8. Plot of the specific degradation coefficients $(1 / \mathrm{sec})$ versus tetralin concentration. 


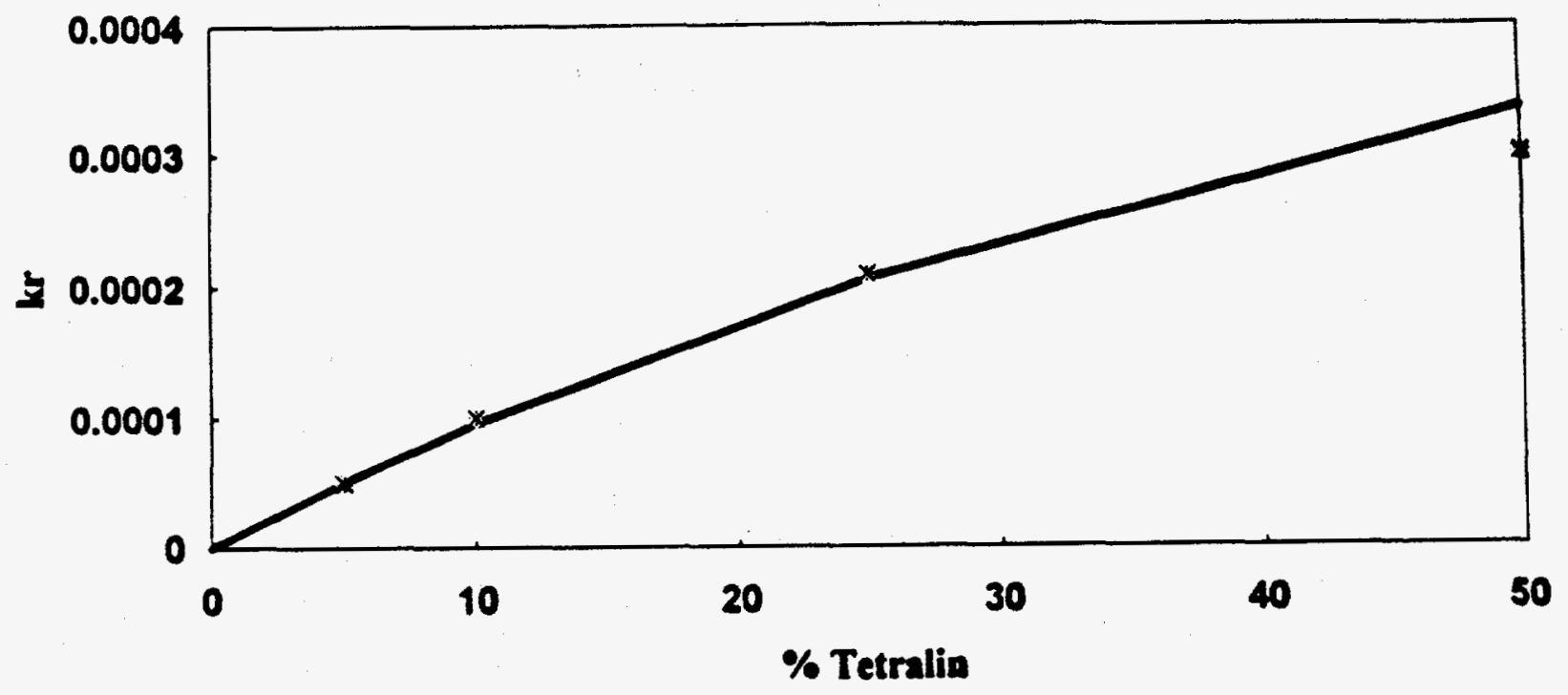

Figure 9. Plot of the random degradation coefficients $(1 / \mathrm{sec})$ versus tetralin concentration. 